\title{
El capital financiero de Rudolf Hilferding y la crisis contemporánea capitalista
}

\section{Finance capital of Rudolf Hilferding and the contemporary capitalist crisis}

\author{
Oscar David Rojas Silva² \\ Universidad Nacional Autónoma de México \\ revistpenscritico.fce@unmsm.edu.pe \\ https://orcid.org/0000-0002-5320-570X
}

\begin{abstract}
RESUMEN
El presente artículo explora los elementos más interesantes de la obra de RudolfHilferding como eslabón crucial para la actualización del análisis de Marx en El Capital para explicar el fenómeno de la crisis financiera en el siglo XXI en el contexto de mudanza de fase histórica. El modo de producción capitalista ha tenido grandes modificaciones en lo productivo, pero también en las relaciones de distribución que se expresan en la forma de propiedad. Las sociedades por acciones, a inicios del siglo XX, irrumpen en la escena económica, destruyendo el esquema tradicional de capitalismo basado en la libre competencia y en las unidades privadas aisladas. Esto nos lleva hacia el mundo contemporáneo donde los grandes oligopolios han terminado de edificar el mercado mundial. Hilferding nos ofrece la categoría de capital financiero como un apoyo para conectar los distintos niveles de abstracción en El Capital hasta su evolución madura, sin esta reflexión metodológica la teoría de la crisis queda presa bajo el economicismo de la ganancia. Al agregar una teoría de la transición histórica ponemos el fenómeno de la crisis en su contexto de mudanza y no como una debacle apocalíptica. El campo económico-social exige apuntar hacia la reflexión sobre el sujeto que habrá de actuar los cambios políticos en la arena pública.
\end{abstract}

(C) Los autores. Este artículo es publicado por Pensamiento Crítico de la Facultad de Ciencias Económicas, Universidad Nacional Mayor de San Marcos. Este es un artículo de acceso abierto, distribuido bajo los términos de la licencia Creative Commons Atribucion - No Comercia_Compartir Igual 4.0 Internacional. (http:// creativecommons.org/licenses/by-nc-sa/4.0/) que permite el uso no comercial, distribución y reproducción en cualquier medio, siempre que la obra original sea debidamente citada. 
Palabras clave: Marxismo; comercio internacional y finanzas; economía financiera; metodología de la economía; orden económico internacional e integración; colonialismo; imperialismo; crisis financieras.

JEL: B14, B17, F54, G01

\section{ABSTRACT}

This article explores the most interesting elements of the work of Rudolf Hilferding as a crucial link for the update of Marx's analysis in his book Capital, in order to observe the phenomenon of the financial crisis in the 21st century. The capitalist mode of production has had great changes in the productive sphere but also in the relations of distribution expressed in the form of property. The joint-stock company breaks into the economic scene by destroying the traditional scheme of capitalism based on free competition and isolated private units. This leads us to the present where the great oligopolies have finished building the world market. Hilferding offers us the category of financial capital as a support to connect different levels of abstraction in Capital reaching its mature evolution. Without this methodological reflection the theory of the crisis falls under the economism of profit. By adding a theory of historical transition we put the phenomenon of the crisis in its historical context and not as an apocalyptic debacle. The economic-social formation requires pointing towards reflection on the subject that will have to act the political changes in the public arena.

Key words: Marxism; Internactional Trade and Finance; Financial Economics; Economic Methodology; International Economic Order and Integration; Colonialism; Imperialism; Financial Crises.

JEL: B14, B17, F54, G01 


\section{Introducción}

El capitalismo es para Rudolf Hilferding (1877-1941) una revolución, una auténtica transformación de la totalidad del sistema social, es una conmoción fundadora de nuevas cualidades y nuevos procesos objetivos, una unidad que despliega las más variadas expresiones en la fenomenología de los agentes económicos, todos estos cambios, además, se revelan siempre inéditos en la vida del género humano.

Un proceso económico no tiene reversibilidad en su tendencia, una vez alcanzada cierta magnitud se trastoca en otro proceso económico ${ }^{3}$, sufre modificaciones cualitativas que no le permiten regresar al estado original. Además, los efectos de su tendencia se pueden retardar, pero no se pueden eliminar. Es por ello que la fenomenología es medular para Hilferding, porque se encuentra consciente de que el modo de producción histórico en cuestión desarrolla distintos aspectos dependientes de sus condiciones particulares históricas, políticas y naturales. Es decir, la noción de modo de producción es una abstracción que permite comprender lo concreto pero que nunca puede sustituirlo, siempre nos encontraremos singularidades en las distintas regiones aún correspondiendo a la misma fuerza histórica básica. Por ejemplo, el hecho de que Alemania desarrollara las sociedades anónimas con mayor profundidad en contraste con la evolución de grandes capitalistas individuales en Inglaterra, tiene que ver con el retraso industrial de esta y la presión exterior de la fuerza exportadora de aquella. Ante una desventaja de adaptación al medio, se estimula la creación de procesos nuevos que antes no eran necesarios, Alemania tenía que competir con Inglaterra y para ello tenía que reunir de forma eficaz cualquier capital individual desperdigado en su incipiente desarrollo para poder competir contra la fuerza de la industria inglesa altamente concentrada. En suma, nacía dadas las condiciones específicas de competencia la forma de negocios que significaría el molde del imperialismo: las sociedades por acciones.

Esta nueva fuerza productiva permitió grados exponenciales de concentración. Dejaron de viajar los activos industriales y se volatilizaron los títulos de propiedad. Esto crea una nueva geografía económica que es necesario abordar. No hablamos de cualquier cosa, la entrada del siglo XX significó la redefinición de la relación espacio-tiempo a escala plan- 
etaria. Esta nueva geografía, entonces, genera impactos diversos en las distintas regiones del globo. La subjetividad y la objetividad corren juntas en el análisis económico hilferdiano, de ahí que la quinta y última sección de El capital financiero se encuentre dedicado a analizar no sólo la política económica del capital financiero, sino también cuál es la política económica del trabajador. ¿Qué se puede hacer frente a las adversidades que representa el modo de producción capitalista en contra del productor real? ¿Quién es el sujeto revolucionario que habrá de romper el círculo vicioso de las crisis económicas?

No tendría ningún sentido explicar, digamos, la diferencia de determinaciones y perspectivas entre el mercado interno y el mercado exterior si no es para solventar la necesidad que el trabajador tiene por comprender y vencer una serie de fenómenos que le obnubilan el reconocimiento de lo que realmente significa una política económica u otra para su enfrentamiento contra la explotación capitalista. Es decir, el capital produce una subjetividad que pierde rango de observación con respecto a la arquitectura general de la economía mundial como una totalidad concreta.

Desde esta óptica me parece que El Capital financiero se instala dentro del fomento de la praxis política como el concepto que responde a la identificación y orientación de las acciones de los trabajadores para lograr una nueva estructura de relaciones sociales dadas las fuerzas productivas generadas por ellos mismos de forma colectiva y, aquí podemos agregar también, el General Intellect, esto es, el conocimiento generado en la cooperación social intergeneracional. Esto une a la discusión del método de Marx una actualización sobre fenómenos nuevos como la economía del conocimiento y los nuevos alcances de las fuerzas productivas. Se trata de agregar elementos cualitativamente nuevos a las discusiones tradicionales sobre la crisis financiera capitalista, las cuales versan primordialmente sobre la restitución de la tasa de ganancia o sobre la explosividad de los derivados como un instrumento financiero maniático.

Hilferding, el economista y médico vienés da una especial atención a la cuestión del Estado como el órgano consciente por antonomasia de los modos productivos, pero aquí debe insistirse en la transitividad histórica 
de contenidos históricos que se pueden distinguir, uno es el tipo de Estado propio del mercantilismo y otro muy diferente del Estado bajo el capitalismo. El sistema ideológico capitalista sigue reproduciendo la misma narrativa que cuando la burguesía se enfrentaba al Estado mercantil, se trata de resolver el problema de los burgueses en su lucha contra el mercantilismo feudal de las grandes compañías de la época, según Hilferding (1973, p.22) menciona que:

La concepción burguesa del Estado nace en la lucha contra la política mercantilista, en la lucha contra el poder centralizado y dispensador de privilegios que es el Estado. Refleja los intereses de la incipiente manufactura y fábrica capitalista frente a los privilegios y monopolios de las grandes compañías comerciales y coloniales, de un lado, y la industria artesana cerrada en forma de gremios, de otro. Pero la lucha contra la intromisión del Estado sólo se pudo llevar con éxito cuando se demostró que la legislación estatal era superflua y perjudicial para la vida económica. Frente a las leyes del Estado tuvo que demostrarse la autonomía legítima de las leyes económicas y su superioridad sobre la legislación estatal.

Dado a que el mundo en ese momento tenía una consciencia de corte colonial, fue una labor de la economía política comenzar a clarificar en qué consistían estas leyes económicas, las cuales tienen su dominio por encima de las decisiones particulares de un déspota, William Petty (1623-1687), por ejemplo, introduce el tema del dinero como una de estas nuevas leyes, inaugurando con ello el problema del valor ${ }^{4}$.

Esta visión de totalidad, más la separación entre leyes objetivas evolutivas y la subjetividad (praxis) desarrollada, representa elementos potentes para el análisis de Hilferding y para todo aquél que se instale desde la perspectiva del materialismo histórico para comprender la realidad contemporánea de la formación económico-social que llamamos capitalismo. Para ello, la obra de Rudolf Hilferding permite identificar la perspectiva que distingue con claridad la esfera del proceso de producción y la esfera de la circulación como un todo en movimiento: el capital social global (CSG). 


\section{La dimensión del valor y el dominio del capital financiero}

Marx, en sus reflexiones metodológicas, identifica la complejidad que significa analizar un sistema por sus partes que por su totalidad; no obstante, el análisis particular micrológico significa analizar científicamente: lograr la concepción esencial de la unidad para comprender la actividad de las partes, es decir, el análisis crítico de la fenomenología real y efectiva. Tal como se le presenta a los agentes económicos en su día a día, en su sentido común.

Hilferding advierte, de igual manera, que con la primera parte de su obra es necesario tener calma y paciencia dado el nivel de abstracción correspondiente, paso necesario para poder fundamentar el arribo a las expresiones fenoménicas. El dinero es, por tanto, identificado como el punto de partida más abstracto por encontrarse dentro de la secuencia básica del intercambio económico, como señala el propio Hilferding (1973, p. 21):

La acción común de las mercancías en el cambio es lo que transforma el tiempo de trabajo privado, individual y concreto del individuo, en tiempo de trabajo general, socialmente necesario y abstracto, que forma valor. Al medirse mutuamente las mercancías en el cambio universal se miden, al mismo tiempo, en una mercancía cada vez con mayor frecuencia. Esta sólo necesita ser fijada habitualmente como escala de valor para convertirse en dinero.

Por tanto, el cambio de valores es necesario para hacer posible toda producción y reproducción social.

El valor es una nueva dimensión que según el arreglo de su tiempo tiene su efecto en su espacialidad. Se devela una red asociativa y co-dependiente, se trata de la categoría esencial de la ley del valor: el tiempo de trabajo socialmente necesario. El valor es una cuestión de tiempo y este no se produce ni se reproduce en abstracto, sino en concreto, dado cierto nivel de fuerzas productivas, en su representación material ${ }^{5}$. Esto habilitará a Hilferding para comenzar a analizar los distintos niveles de dichas fuerzas y sus efectos en la organización material técnica de la sociedad: a diversas magnitudes, expresiones cualitativas diferentes. 
El valor funge como la dimensión donde la magnitud de las fuerzas productivas producen determinado tipo de organización social, esto en contraste a la visión atomizada donde el valor es fijado de forma individual por motivos de carácter estrictamente subjetivos, nuestro autor identifica al trabajo socialmente necesario como el punto de referencia colectivo desde la visión ontológica de la sociedad. Sin esta base sólida de referencia sería imposible ordenar, por ejemplo, el mecanismo de la Bolsa de valores, la estabilización capitalista se alcanza en tanto se alcanzan nuevas funciones sociales: el crédito y el tipo de interés. Estas son funciones de una unidad económica mundial con un tiempo de acumulación de capital tendiente a la infinitud. Aquí reside la base que fundamenta la posibilidad de que el capital dinerario se autonomice eventualmente hasta estallar como lo vimos en la crisis del 2008.

Por otra parte, es necesario recordar que Hilferding fue un férreo defensor del materialismo histórico frente a los ataques de Böhm-Bawerk (1974) a dicha teoría, el punto reside en que éstas críticas plantean una supuesta desconexión contradictoria entre el Tomo I de El Capital y el Tomo III; esto significaría que el análisis de la ganancia no es derivable del análisis del plusvalor, con ello se argumenta que las conclusiones del análisis marxista están equivocadas y que los intercambios mercantiles tendrían la posibilidad de significar una cosa distinta a la explotación, se intenta borrar por todos los medios de la derivación de plusvalor, antes bien -indican los teóricos neoclásicos- el valor puede venir de una valoración psicológica utilitaria ${ }^{6}$. No obstante, en la obra de Hilferding existe un paso suave y terso (dialéctico) entre las distintas determinaciones del plusvalor, no sólo entre plusvalor y ganancia, sino especialmente entre ganancia e interés. Esto permite comprender cómo articular los distintos niveles de análisis del materialismo histórico para poder tematizar holgadamente sobre la estructura del sistema de crédito mundial como una función social ya desarrollada.

Aquí es relevante insistir en que los procesos sociales tienen una esencia biológica en el sentido de que una vez haciéndose material su esencia entran, de inmediato, en un proceso acelerado de descomposición. Estos principios observados por Hilferding desde inicios del siglo XX se terminan - pasando, por supuesto, por la evolución del sistema Bretton Woods- con la crisis del 2008. En palabras de Óscar Ugarteche (2018, 
p.38) en su reciente libro Arquitectura Financiera Internacional: una genealogía (1850-2015) señala:

El orden económico internacional de posguerra, donde Estados Unidos se convirtió en el líder hegemónico y con su moneda como reserva y sus leyes universales impuso un sistema de créditos internacionales y afianzó un sistema de comercio internacional basado en su moneda. Esto ha llegado a su fin con la conversión de dicho país en el deudor más grande del mundo.

Recordemos que el análisis de la obra del Capital financiero es retomada puesto que fija moldes nítidos sobre el tipo de organización económica que se funda en el siglo XX. La buena nueva que tenemos desde el tiempo presente es que esta forma social ha llegado a un límite cualitativo.

El corazón central de El Capital financiero es distinguir con precisión el tránsito entre el capital privado individual hacia las sociedades por acciones, para ello se analiza el papel dinámico del crédito en la circulación, sus relaciones crediticias primero centradas en la necesidad del capital industrial (o productivo) hasta alcanzar el límite donde se crea la imposibilidad de que el plusvalor extraído pueda convertirse una vez más en capital de nueva cuenta. Así, surge la conceptualización de capital congelado o latente que pondrá a la banca como un actor principal en la forma en la que el sistema busca saltar sus propias barreras mediante la constitución del capital ficticio ${ }^{7}$ como toda un área nueva para la modificación del tiempo y espacio en los intercambios económicos mundiales. Es decir, Hilferding ubica con claridad, dentro del esquema de totalidad del materialismo histórico en qué momento está situada la particularidad del capital ficticio como una nueva fuerza productiva que permite nuevos mecanismos de crédito.

La diferencia entre valorización y capitalización es crucial. Como se podrá recordar, el Tomo III de El Capital de Marx (2016) comienza distinguiendo la ganancia del plusvalor basado en la medición subjetiva que el capitalista hace de su capital adelantado, este no distingue entre capital constante y variable, sino que la ganancia la atribuye al conjunto mismo. En la segunda vuelta de tuerca dialéctica a esta relación subjetiva-objetiva tenemos que a esta medición fetichizada sobre la tasa de beneficio 
deviene la capitalización, pero ahora mediante la estructura de sociedad por acciones, los participantes accionarios se contentan con obtener ya no la tasa de beneficios sino el rendimiento promedio del tipo de interés establecido.

Estos títulos fijados sobre la esperanza futura de acumulación abren un nuevo mercado para el capital ficticio: la bolsa de valores. Éstos pasos sutiles en el análisis son de relevancia crucial para el análisis de las crisis financieras en el siglo XXI ya que habilita elementos de inter-conexión medular entre la fenomenología a la que estamos ya acostumbrados a escuchar en los medios de comunicación sobre las alzas, las bajas y las caídas bursátiles, con la mismísima teoría objetiva del valor de Marx.

Pero no sólo se trata de su forma organizativa técnica, sino también de la noción del sistema bursátil como fundamento central del desarrollo del imperialismo. Incluso autores liberales como Max Weber (2013, p.109), uno de los promotores de la modernidad capitalista, acepta el papel como herramienta de batalla geopolítica de la Bolsa de valores:

Una Bolsa fuerte no puede ser precisamente un club para la $<<$ cultura ética $>>$, y los capitales de los grandes bancos son tan poco $<<$ instituciones benéficas >> como puedan serlo los fusiles y cañones. Para una política económica que aspire a alcanzar fines en esta dirección, aquéllos sólo pueden ser una cosa: instrumentos de poder en la lucha económica.

Más aún, al interior de la estructura de la Bolsa se encuentra organizada para que los títulos y las decisiones especulativas se decidan por apenas una fracción mínima de los participantes. En esta segunda sección intitulada La movilización del capital. El Capital ficticio existe además una de las categorías innovadoras de Hilferding: la ganancia del fundador. Se refiere a que en toda formación de una sociedad por acciones, la cual habilita el levantamiento del edificio bursátil existe siempre una "renta" específica para los que llevan a cabo emisión de títulos de propiedad bursátil, es decir, existe una tendencia a la concentración de los rendimientos (y por tanto el control sobre los beneficios industriales) en los fundadores de las sociedades por acciones; se genera la posibilidad, a diferencia de lo que sucede con el capital industrial individual, de controlar cada vez 
montos mayores de capital sin la necesidad de tener la propiedad total del capital en cuestión, dicho mercado nace cargado hacia la concentración, con diferentes tipos de acciones que construyen los propietarios de acciones permitiendo la toma de decisiones sobre los negocios y una cantidad de pequeños accionistas que especulan ciegamente en dicho mercado, esquilmados cada cierto tiempo por la dirección especuladora, la cual tiene una mayor información y conocimiento específico sobre el estatus de los negocios.

Así, en este mercado de comercio de títulos se inscribe lo ficticio del capital, pero en su sentido de competencia y de transferencia de rentas, Hilferding (1973, p.113) lo pone de la siguiente manera:

la acción es, pues, un título de renta, un título de crédito sobre la futura producción, una asignación sobre los rendimientos. Capitalizando estos rendimientos y constituyendo esa capitalización el precio de la acción, parece existir un segundo capital en estos precios de acciones. Esto es puramente ficticio. Lo que existe realmente es sólo el capital industrial y sus beneficios.

Así, partiendo de la noción de acciones se genera el mercado que tiene como principio sistémico el de lograr la movilidad del capital. La tendencia del capital es a desprenderse de sus amarras geográficas mercantiles y fundar esta nueva dimensión geográfica basada en campos monetarios. La tendencia al aumento de la composición orgánica del capital en el capital industrial provoca que sea difícil movilizarse geográficamente e inter-ramas, por lo que la forma de movilización se realiza mediante el mercado de títulos de plusvalía capitalizadas -como le llama Hilferding-, produciendo, por un lado, la constitución de la tasa media de ganancia (ley del mercado capitalista), pero también la construcción de un espacio económico virtual distinto, la movilización del valor mediante el cambio de manos entre propietarios.

Cabe destacar que, gracias a la ganancia del fundador y a los procesos de concentración y centralización que se expresarán en la formación de comunidades de intereses (cartel y trust), el mercado por donde se mueve el capital está arquitectónicamente desequilibrado, tiende a la concentración de grandes capitales y a la constante estafa y quiebra especulativa de pequeños capitales. Me parece que esta noción ayuda a comprender la 
forma en la cual hoy se sigue concentrando la propiedad. Este tema ya ha sido incluso puesto sobre la mesa por economistas del mainstream como Thomas Piketty ${ }^{8}$. Al imaginario de la propiedad de la tierra o la propiedad de los medios de producción se puede agregar la categoría de propiedad monetaria como un punto de apoyo para el análisis concreto de las crisis financieras. Esto, mezclado con el reconocimiento del uso geopolítico de la Bolsa como un instrumento de guerra económico, tenemos que la crisis del 2008 no se trató de un error o exceso especulativo sino de un síntoma de la guerra económica entre potencias.

Es por ello que observamos en la Bolsa toda una narrativa de estafa y de grandes debacles financieras de prestigiosos especuladores. El propio mercado ficticio crea los actores económicos que serán sacrificados sistemáticamente en las crisis. Así, ya no se trata de la imagen tradicional donde el capitalista explota al trabajo (que lo sigue llevando a cabo en sus fundamentos) sino que se devela también la relevancia de la explotación rentística de unos capitales sobre de otros.

Así, podemos decir, que en las crisis bursátiles se sacrifican a unos capitalistas (capas pequeñas y medias) para el fortalecimiento de los gigantes, no por una suerte de talento especulativo y de medición de riesgos (lo que representa una total farsa ideológica) sino por la propia estructura de la acumulación capitalista cuando se expresa en su conversión de capitalización a interés.

Dicha transmutación dialéctica es una de las bases analíticas de Hilferding, punto de crucial importancia para la clarificación del análisis que Marx desarrolla en su inspección de la fórmula trinitaria donde las tres clases sociales del modo de producción capitalista, los terratenientes, capitalistas y trabajadores tienen su rendimiento medido en renta, ganancia y salario, pero en el caso particular de la ganancia se plantea que la fórmula final tiene que ver con su conversión al interés. Dicho de otra manera, los agentes económicos enfrentan subjetivamente sus mediciones económicas basados en los rendimientos y no sólo en la tasa de beneficios. Nada de esto, como se puede observar en el análisis lógico de Rudolf Hilferding contraviene a la teoría objetiva del valor, antes bien, gracias a este análisis, el médico y economista vienés ayuda a clarificar en qué sentido el interés es la última autonomización del capital en la secuencia 
plusvalor $\rightarrow$ ganancia $\rightarrow$ interés. Este punto es de gran relevancia toda vez que ayuda a centrar en este proceso de autonomización y de generación de una fenomenología particular en el mercado ficticio que acompaña la crisis mundial que padecemos actualmente.

Hilferding provee de una taxonomía de los capitalistas, la libre competencia que se encuentra en la concepción tradicional del capital tiene ya más de un siglo que ha dejado de existir, los nuevos actores basados en las sociedades por acciones tienen una variedad de expresiones y no pueden ser considerados de forma aislada como capitalistas individuales. El imaginario de la crítica de la economía política no llega muy lejos si sólo parte de esta individualidad -analizada con justeza y como fundamento en el tomo I de El Capital- sino en la complejidad de la unidad diversa -correspondiente al análisis del Tomo II y III de la cuál la obra de Hilferding es tributaria directa-.

Se trata de una serie de asociaciones homogéneas o combinadas, parciales o totalmente monopolizadas, estructurada como una comunidad de intereses donde cada elemento mantiene su independencia relativa o como una fusión total. Hilferding apunta al hecho de que para su época, comienzos del siglo XX, costaba trabajo aceptar las tendencias de concentración y centralización enmarcadas en El Capital de Marx. La característica estructural de estas nuevas combinaciones es que se vuelven altamente dependientes del capital monetario, los capitalistas industriales se desdoblan y generan un empresario industrial que no tiene la propiedad del capital, sino que sólo lo administra, los verdaderos dueños se encuentran en la gestión del capital financiero. No sólo es El Estado el organismo consciente, sino que ahora lo acompañan las estrategias de competencia y cooperación de los grandes carteles y trusts que mediante el capital monetario personificado por los bancos gestionan el destino del capital social global como un conjunto dimensional, aún constreñidos, por supuesto, a los fundamentos de la acumulación capitalista con todas sus contradicciones. De ahí que Hilferding (1973, p.225) señale:

La movilización del capital y la expansión cada vez mayor del crédito van cambiando completamente la posición de los capitalistas monetarios. Crece el poder de los Bancos, se convierten en fundadores y, finalmente, en dominadores de la industria, apoderándose 
de los beneficios como capital financiero, igual que arrebataba antes el usurero con su <<interés >> el rendimiento del trabajo de los campesinos y la renta del latifundista. El hegeliano podría hablar de la negación de la negación: El capital bancario fue la negación del capital usurero y es negado a su vez por el capital financiero. El capital financiero es la síntesis del capital usurero y del capital bancario y, como éstos, aunque en un grado infinitamente superior del desarrollo económico, se apropia de los frutos de la producción social.

Siguiendo esta ruta hegeliana, así como el trabajo libre asalariado es la negación del esclavismo, en tiempos de la dominación del capital financiero tendríamos también la necesidad de conceptualizar una nueva negación del trabajador libre asalariado, toda vez que el capital financiero tiene por característica la explotación de todo el capital social, también universaliza la explotación sobre el trabajador colectivo global, éste incluye a nuevas capas que aparentemente pertenecen a la burguesía pero que han sido despojadas también del control de su propiedad. Este puede ser el sentido de lo que señala Hilferding en tanto la apropiación de todos los frutos de la producción social.

Hilferding explica a detalle en la tercera sección de su libro cómo es que este capital financiero representa la limitante de la competencia en el sentido clásico del modo de producción capitalista; no está demás señalar que no es que hayan desaparecido los capitalistas individuales, sino que estos han sido subsumidos, dominados por un poder mayor; la acumulación capitalista, persecutora de ganancias extraordinarias intenta romper todas las barreras que se le presentan, así el capital privado representó una barrera al propio capital por lo que el proceso de expropiación y de asociación fue la única manera de continuar el proceso incesante de valorización.

Lo que aquí señalo es que el proceso de subsunción implica la refuncionalización de procesos que si bien en algún momento han sido dominantes ahora entran en el área de influencia de un nuevo proceso, este movimiento lógico de la negación de la negación es un proceso histórico de tendencia de largo plazo. Lo que Hilferding está señalando a inicios del siglo XX es un proceso que se perfecciona a lo largo de todo el siglo y estalla durante los primeros años del siglo $\mathrm{XXI}^{9}$. 
Lo que hay que notar es que la nueva movilidad del capital gracias a la estructura del mercado bursátil implica que lo que se mueve ya no son sólo las mercancías preñadas de plusvalor, sino el capital mismo, así como el origen histórico pone como base al capital comercial, este termina subsumido al capital financiero, la política comercial como se ha mencionado sigue siendo relevante pero es incomprensible si no se parte del hecho de que su motor de movimiento se encuentra en los movimientos mismos del capital, en la forma de intercambio de títulos de renta, el capital se mueve buscando nuevos espacios económicos para combatir la tendencia a la baja de la tasa de beneficios. Este nuevo movimiento construye una red mundial que pasa por encima de las fronteras de los estados-nación. Nacen los famosos fondo buitre.

La unidad del capital se vuelve mundial y utiliza sus distintas partes como los mecanismos para acrecentar y fundamentar esta red. Hilferding (1973, p.248) resume esta nueva relación inter-capitalista con una ilustración: "el capital industrial es el Dios Padre que ha dejado como Dios Hijo al capital comercial y bancario, y el capital monetario es el Espíritu Santo; son tres, pero uno solo en el capital financiero". En suma, todo capital social es susceptible de especulación financiera. Este es el origen de la vulnerabilidad con el que hoy la economía pública depende de Wall Street ${ }^{10}$. Esta dependencia absoluta es la que está contenida bajo la categoría económica de "imperio financiero". Hilferding, utilizando el materialismo histórico con mucha seriedad, logra delinear el tipo de relación de dominio que se volverá determinante a inicios del siglo XXI.

Hilferding, fiel a la tradición categorial del materialismo histórico observa tendencias, no sólo se trata de lo que aparece o no empíricamente, sino que se preocupa de las trayectorias lógicas a largo plazo. Un punto central es considerar el tema de la escala del sistema capitalista de asociación. El año de 1895 fue un año donde todas las potencias capitalistas, sin excepción, crecieron exponencialmente, la verdadera primavera del capitalismo llegó a uno de sus picos más altos en esos momentos; no obstante, nuestro autor logró plantear con plena confianza en la lógica establecida en sus estudios la continuación de la tendencia y resultado ineludible del proceso de acumulación -aún en su apariencia de mayor éxito-: la crisis capitalista. 
Pero también el militarismo y el choque inter-carteles-trusts inherente a la competencia-cooperación de las potencias. El inicio del siglo XX continúa su secuencia de producción de mercado mundial. Se trata de la competencia por el espacio económico mediante el despliegue del campo monetario, los países cuentan con un mercado interior y una necesidad de competencia en el sector externo; la economía mundial, por tanto, estará definida por el militarismo ${ }^{11}$ y por la dirección estratégica del capital financiero, esto es: la socialización del capital en forma consciente, con autonomía estratégica.

Hilferding da un paso adelante en la tendencia detectada por Marx sobre el proceso de conversión basada en la expropiación de los expropiadores. Las distintas experiencias capitalistas de los países en el siglo XIX logran transmitirse unas a otras y formar un modo productivo mundial donde las distintas características dada la competencia se fueron desarrollando, las guerras mundiales son, con ello, una expresión de la tendencia a la mundialización y la lucha por el espacio económico mundial. Esto significa que la proyección del espacio-tiempo que acompañaba la estructura de libre competencia queda superada y se instala ahora en una constante lucha por el espacio económico que, además de las necesidades básicas de la producción agrícola, recursos naturales y trabajadores disponibles, se instala también un espacio virtual económico del valor, el terreno por donde corren los distintos títulos de propiedad en el globo. Me parece que la perspectiva hilferdiana permite, pues, construir la concepción de una nueva geografía económica, y con ello reconocer las nuevas proyecciones del espacio-tiempo que acompañarán a la competencia-cooperación oligopólica y monopólica a escala mundial.

Para Hilferding, el tema de la crisis reviste una importancia medular (le dedica toda la cuarta sección), parte del análisis del esquema de reproducción ampliada, éste análisis "microeconómico" permite fijar las condiciones generales de la crisis y su inteligibilidad a escala mundial y, particularmente, la del supuesto de equilibrio que acompaña la acumulación capitalista. La anarquía de la producción es relativa en tanto existe una necesidad intrínseca de los agentes económicos (asociados o no) por mantener un proceso de reproducción entre la esfera económica de medios de producción y de la de consumo en formación perpetua de capital. 
No se trata sólo de la extracción de plusvalía sino particularmente de las posibilidades de reconvertir la plusvalía generada en capital de nueva cuenta. Este es el punto más frágil y vulnerable de la circulación capitalista. Hilferding demuestra lógicamente cómo el capital puede dar el salto de la reproducción simple a la ampliada sin ningún problema, siempre y cuando se cumplan las transacciones de equilibrio entre ambos departamentos de la economía, esto es, en tanto se respeten las proporcionalidades, pero también distingue que a una mayor fuerza productiva se genera un mayor capital productivo virtual y un capital monetario virtual también más amplio. Con una base monetaria de patrón oro -vigente en el tiempo de Rudolf Hilferding- el proceso de acumulación creciente demandaría mayor dinero para enfrentar una nueva magnitud de masa productiva y también un nuevo nivel de circulación, esto dependería del nivel de extracción de oro que pudiera acompañar el proceso general.

El capital logra saltar esta limitante prescindiendo de la base oro, mediante el desarrollo del sistema de crédito, es decir, el mercado de capital ficticio vuelve más elástico la posibilidad de la circulación para acompañar la nueva magnitud productiva. Hilferding, con este argumento, aclara que las crisis no tienen su origen en el subconsumo (problemas de demanda naturales al capital por el antagonismo salario-ganancia) ni de sobreproducción de mercancías, sino que el punto crucial se encuentra en la capacidad del sistema por absorber fuerzas productivas cada vez más potentes, recordemos que cada ciclo representa una mejora tecnológica general que eleva la composición orgánica del capital y con ello la disminución de la tasa de beneficio; mientras que el plusvalor alcance la magnitud requerida para poder valorizarse, este se encuentra necesariamente congelado o latente en forma monetaria, en forma improductiva, lo que va formando un gran peso muerto en el sistema que no tarda en representar una inversión en la tendencia de la acumulación, la imposibilidad de transformar plusvalor congelado en capital actuante dado cierto nivel de fuerzas productivas, se rompe el equilibrio y se genera la crisis ${ }^{12}$. A la superproducción de capital productivo le surge su par: la superproducción de capital monetario. Surge la burbuja financiera. Hilferding (1973, p.285) realiza una cita extensa de Marx donde se explica en el Tomo II la cuestión, he aquí un fragmento de dicha cita: 
[el producto adicional]en su transformación monetaria -como tesoro y únicamente capital monetario virtual en continua formación-, discurre en esta forma paralelamente al proceso de producción, pero yace fuera del mismo. Es un peso muerto (dead weight) de la producción capitalista. El ansia de hacer utilizable esta plusvalía, que se acumula como capital monetario virtual, tanto para el beneficio como para la renta, encuentra la meta de su aspiración en el sistema de crédito y en los $<<$ papelitos $>>$. Así, el capital monetario recibe en otra forma la influencia más enorme sobre el transcurso y el potente desarrollo del sistema de producción capitalista.

Así, la crisis del capital financiero es expresión de la desproporcionalidad tendencial que el proceso de acumulación va generando en su camino. El sistema de crédito mundial produce una elasticidad inédita en el desarrollo del mercado mundial. Hilferding tiene claro, al mismo tiempo, que esta tendencia tiene un proceso cíclico que reinicia después de la crisis, es decir, se generan siempre nuevas condiciones para el nuevo proceso de acumulación, es un nuevo punto de partida. Es por eso que el fenómeno de la crisis no se puede analizar de forma aislada sino sólo como el reverso del proceso de acumulación, y todavía más, siempre en términos de una crisis de mercado mundial, por ello Hilferding advierte que en el análisis de la crisis no se pueden derivar sus leyes si se analiza sólo un país o aspectos parciales, toda vez que la interdependencia del mercado mundial aumenta, las leyes derivables sólo son posibles en la escala de la unidad económica en su totalidad y además analizando la concepción de capitalismo como una unidad planetaria mediante la categoría de capital financiero.

Hasta aquí hemos enfatizado el rol central del capital financiero como la expresión más desarrollada del capital como modo productivo histórico. Ahora toca analizar cómo este poder realiza su dinámica mediante los movimientos de exportación de capital. Recuerde el lector que aquí se trata de develar la diferencia que existe entre el modo de producción capitalista del siglo XIX basado en el capital privado a la forma dominante en el siglo XX de las sociedades por acciones. Estas últimas se ordenan conforme a los distintos estados-nación que los contienen formando unidades llamadas trusts capitalistas nacionales. Dependerá el tipo de relación que tengan entre sí lo que determinará la estructura hegemónica del sistema. 


\section{La exportación del capital}

El capital financiero de Rudolf Hilferding es un excelente puente entre el desarrollo teórico de Marx, llevado a cabo en el corazón del siglo XIX y recuperando, a su vez, las tendencias del sistema a inicios del siglo XXI. Pero como es propio de las obras basadas en el materialismo histórico tienen un rango más amplio de inteligibilidad, Hilferding, después de todo, está demostrando que las leyes del movimiento capitalista desarrolladas por Marx tienen concordancia con los eventos que vinieron después ${ }^{13}$. El capítulo XXI intitulado Transformación de la política comercial me parece con un gran potencial para la actualización de los análisis que hoy se realizan sobre la geopolítica. Para Hilferding es importante mostrar cómo es que existe una transformación del capital basado en la individualidad privada (capitalismo inglés) hacia la de la sociedad por acciones (al estilo continental) dentro de un proceso de mundialización.

En ese sentido, una de las consecuencias de la nueva fase capitalista basada en las sociedades por acciones es que su potencia adquiere una magnitud mundial, es decir, puede optar por la conquista del espacio económico en el planeta. Así como en la fase anterior mercantilista se generó la política colonial mundial con grandes compañías como la de las Indias Orientales, por citar un ejemplo, en la conformación imperial del siglo XX se desarrolla un tipo de política comercial. Hilferding analiza cuál es la política comercial de la fase del imperialismo capitalista, es decir, describe el mecanismo entre mercado interior y mercado exterior de los estados-nación cruzados por la fuerza trasnacional de los cartels y trusts capitalistas nacionales.

La política comercial del capitalismo financiero ayuda a explicar la geopolítica actual. La lucha por el espacio económico se puede observar en los cuadernos contables de los capitales que viajan por el globo y su nueva geografía y se introducen en distintos territorios en búsqueda de tasas altas de beneficio, espacios donde puede suspender la competencia (definición técnica de los carteles y trusts) y dominar las fuentes de renta y beneficio a través de las distintas fronteras. Estas nuevas unidades económicas son cualitativamente distintas que nuestro imaginario de una empresa individual en el sentido clásico. Ahora el poder de esta coagulación ha subsumido el actuar del Estado y lo ha sometido a sus necesidades estratégicas. 
Los conceptos relevantes para analizar la política comercial de la nueva fase del capital financiero es el tránsito entre el arancel educativo -utilizado para proteger los estados-nación de la fuerza productiva de otros hasta que la industria estuviese los suficiente madura para poder competir- al arancel proteccionista cartelizado - un instrumento para poder competir con mayor fuerza y controlar espacios económicos en disputa. Este último, es -a decir de Hilferding- una forma de volverse más competitivo sacrificando las condiciones de vida del mercado interior. El encarecimiento de las mercancías gracias a un arancel habilita la posibilidad de vender más barato en el exterior, el mercado interior en su conjunto se convierte en una máquina para la batalla del capital financiero en la arena mundial. Esto es muy grave puesto que subsume el proceso vital de los productores reales a las necesidades de valorización y especulación de alta velocidad y magnitud. Es por ello que la crisis del 2008 representó no la pérdida de capitales privados en competencia sino una destrucción de valor colectivo, una desvalorización del capital social global.

El Estado, dentro de esta discusión, no toma un papel regulador entre intereses privados y los del trabajador (productor real) (Hilferding dedica un capítulo a la discusión sobre la lucha de la jornada laboral), sino un papel de gestión del capital financiero que se lanza al dominio del espacio económico mundial y que además usa todo lo que esté en sus manos para poder someter al mercado interior a los intereses del sector exportador. Estos rasgos son los que sostienen, por ejemplo, el modelo neoliberal que México adoptó después de los años ochentas. El neoliberalismo, desde esta perspectiva, significa la entrega total de la economía nacional a una reconfiguración de la base productiva para privilegiar al sector exportador. Es el sacrificio del mercado interno en pro de mantener niveles suficientes para la especulación del capital financiero.

La idea central de este mecanismo es que la exportación permita producir plusvalía en el mercado extranjero y que habilite su transferencia desde los países terceros hacia el país de origen. Esta característica conlleva, sin duda, el germen de la guerra mundial ya que toda ganancia va en detrimento del otro. El militarismo se vuelve necesario para poder garantizar la soberanía sobre los espacios económicos ganados económicamente. El conflicto está asegurado porque el espacio económico a conquistar es ajeno, es un espacio que en su estructura legal goza de soberanía política. 
Así como existe la explotación de un humano sobre de otro humano, se genera una explotación entre organizaciones económicas sociales, digamos más fácilmente, una explotación de un país por otro país, el principio de la propiedad privada capitalista en su fase del capitalismo financiero y como este dominio se asegura mediante el monopolio del sistema de crédito internacional (sistema fiat-dólar) entonces hablamos de una propiedad privada monetaria. Esto acelera las capacidades de explotación que, al mismo tiempo que implican este férreo control sobre otros países, genera una noción de optimismo y triunfalismo ideológico sobre la capacidad explosiva del capital para reproducirse, Hilferding (1969, p.357) señala:

La exportación de capital acelera la puesta en explotación de los países extranjeros y desarrolla ampliamente sus fuerzas productivas. Al mismo tiempo, aumenta en el interior la producción que tiene que suministrar aquellas mercancías que se envían al exterior como capital. De esta forma, se convierte en una poderosa fuerza motriz de la producción capitalista, que, con la generalización de la exportación de capital, entra en un nuevo período de impetuosa e irresistible actividad (sturm un Drang), mientras que reduce el ciclo de prosperidad y depresión, y la crisis aparece suavizada. El rápido aumento de la producción crea también un aumento de la demanda de fuerza de trabajo que favorece a los sindicatos obreros; la tendencia a la pauperización inmanente en el capitalismo parece vencida en los países de alto desarrollo capitalista. La rápida crecida de la producción impide una visión clara y consciente de los males de la sociedad capitalista y crea un juicio optimista con respecto a su fuerza vital.

Hilferding no habla de la superación de la política colonial mercantilista sino de cómo la política comercial del capital financiero se convierte en una forma superior de política colonial. Una idea interesante en este capítulo es que señala que el capitalismo no brotó en todos los países en distintos momentos -la narrativa tradicional de quienes buscan naturalizar la forma capitalista- sino que fue "importado", los capitales que llegaron a refuncionalizar las otras formas sociales (generalmente por métodos violentos) para expandir los mercados llegaron del exterior. 
El resultado es que esta forma de exportación de capital conlleva mecanismos también para sujetar a los países por medio de la deuda, existen compromisos de compra o acuerdos de compra de un país, por ejemplo, que compra deuda pública de un Estado. Lo curioso es que la categoría de ganancia de fundador que surge en el ámbito de la formación del mercado bursátil, se repite en la exportación de capitales, los países industrializados de donde proviene esta forma social llevan siempre una ventaja en sus propias exportaciones. Tal es el caso de Inglaterra, Francia, Alemania, etc. pero ya desde aquella época figuraba con claridad el surgimiento de Estados Unidos como una potencia imperial de relevancia, incluso es mencionada la doctrina Monroe prefigurando cómo toda América era un campo potencial para la exportación de capital estadounidense. La Segunda Guerra Mundial y el control que el país nor teamericano tomaría mediante el dominio del sistema monetario internacional dan cuenta de la capacidad de análisis y actualización que surge del materialismo histórico. Hilferding hurgaba en el futuro.

\section{Sujeto Universal Revolucionario (a manera de conclusión)}

No tardaría mucho tiempo después de la publicación de esta obra para el crack de 1929. Desde la perspectiva del capital financiero esta crisis es un choque sistémico pues muestra cómo el proceso de exportación de capital termina necesariamente en un quiebre en la acumulación capitalista. La Segunda Guerra Mundial se tratará de la competencia decisiva entre los dos grandes alumnos de Inglaterra: Estados Unidos y Alemania. El triunfador de este conflicto comenzó entonces la construcción de un sistema de dominio sobre la mayoría de los canales de exportación de capital. Desde esta perspectiva me parece que esta obra efectivamente construye el puente lógico de análisis sobre el proceso de transición entre el libre cambio y el capital financiero basado en la anulación de la competencia mediante carteles y trusts en la lucha por el espacio económico.

En suma, Hilferding ofrece una serie de instrumentos categoriales sustentados firmemente en el materialismo dialéctico, para analizar la trayectoria del imperialismo estadounidense, la posibilidad de conectar los movimientos militares, comerciales y bursátiles permiten que se le pueda dar vida y actualidad a la siempre atacada y generalmente incomprendida ley objetiva del valor de Marx. La crisis del 2008 es una expre- 
sión nítida de la teoría de la crisis de Marx, las características actuales de desigualdad extrema y de la crisis climática develan el cumplimiento de la ley de acumulación capitalista: el capital se vuelve el límite de sí mismo, es momento de rediseñar las relaciones sociales de producción.

¿quién hará este rediseño? ¿cómo se hará? ¿Qué mediaciones y pasos habrá que dar para materializar una transformación cualitativa de la realidad económica? Toda esta revisión de la memoria crítica del capitalismo financiero quedaría incompleta si no se conecta con una reflexión sobre la necesaria revolución ideológica -como solía decir Nicolai Bujarinpara comprender las rutas de acción práctica para producir los cambios sociales según el nivel alcanzado de fuerzas productivas. La crisis del 2008, desde su perspectiva tecnológica, es expresión de que existen nuevas fuerzas productivas listas y que chocan con el tipo de relación social dominante, es decir, fuerzas colectivas socializadas chocan con la forma privada de apropiación del producto. Una vez teniendo esto en claro es momento de plantear el papel del sujeto revolucionario. ¿quién habrá de ejecutar estos cambios latentes?

Este tema, sin duda, da para otro artículo, pero por lo pronto, recupérese el hecho de lo que actualmente estamos experimentando en América Latina. Una serie de levantamientos sociales han puesto en jaque las estructuras tradicionales del Estado. Como recientemente indicaría Boaventura de Sousa Santos ${ }^{14}$, ni siquiera la democracia liberal es compatible con las necesidades de acumulación del capital. Han sido los pueblos los que han salido a detener las políticas neoliberales. Lo interesante aquí es que, a diferencia del pasado, no ha salido un sector particular de la sociedad, sino que ha existido un levantamiento transversal del pueblo como un conjunto. Esto denota, por un lado, el alcance de la universalidad de la asociación de trabajo (todos sufren las mismas condiciones generales de producción) pero además surgen reivindicaciones colectivas, de lo humano, la opción por la vida. El sujeto revolucionario es entonces el conjunto de productores reales, inter-género, inter-generacional (jóvenes y adultos mayores) e inter-regional (indígenas y mestizos). Será necesario en el futuro habilitar un análisis sobre la fuerza que ha demostrado al enfrentar a las fuerzas coercitivas de la violencia del Estado y una reflexión antropológica del sujeto llamado pueblo como un sujeto universal revolucionario. 


\section{Referencias bibliográficas}

Bujarin, Nicolai (1969). La economía mundial y el imperialismo. Editorial Ruedo Ibérico: París.

Fischbach, Franck (2012). De cómo el capital captura el tiempo. en Fischbach, Franck (coordinador), Marx, releer El Capital, Ediciones Akal, España.

Gortari, Elí (1979). Introducción a la lógica dialéctica. Grijalbo: Ciudad de México.

Hernández, Juan (2015). Los fondos buitre, capitalismo depredador: negocios y litigios financieros: de Argentina a Grecia. Editorial Clave Intelectual; Madrid.

Hilferding, Rudolf (1973). El capital financiero. Ediciones El Caballito: Ciudad de México.

López, Pedro (2006). Capitalismo y crisis: la visión de Karl Marx. ITACA \& UNAM: Ciudad de México.

Marx, Karl (2001). El Capital: El proceso de producción del capital. Tomo I, Vol. I. Siglo Veintiuno editores: Ciudad de México.

Marx, Karl (2016). El Capital: El proceso global de la producción capitalista. Tomo III, Vol. 6. Siglo Veintiuno editores: Ciudad de México.

Marx, Karl (1980). El Capital: El proceso global de la producción capitalista. Tomo III, Vol. 7. Siglo Veintiuno editores: Ciudad de México.

Bohm-Bawerk, Eugen (1974). "La conclusión del sistema de Marx" en Economía burguesa y economía socialista. Cuadernos de Pasado y Presente, No. 49. Córdoba.

Treviño, María de Lourdes, (2011). Tres décadas de escándalos financieros: are Derivatives to Blame? UANL \& Porrúa. México.

Ugarteche, Oscar (2018). Arquitectura Financiera Internacional: una genealogía (1850-2015), Akal, México

Recursos electrónicos:

Bassets, Marc, (24/11/19), [Entrevista a Thomas Piketty]. Thomas Piketty: Propongo un impuesto que permita dar a todo el mundo 120.000 euros a los 25 años". El País, url: https://elpais.com/elpais/2019/11/22/ ideas/1574426613_189002.html

Chacón, Vinicio (24/11/19) [Entrevista a Boaventura de Sousa Santos], El Neoliberalismo esta mostrando su nueva fase, la incompatibilidad con la democracia, Semanario Universidad, url: https://semanariouniversidad.com/ universitarias/el-neoliberalismo-esta-mostrando-su-nueva-fase-la-incompatibilidad-con-la-democracia/ 


\section{OSCAR DAVID Rojas SiLVA}

\section{Notas al final}

1 El presente artículo es una reflexión sobre la relevancia de la obra de Hilferding en el marco del desarrollo de mi tesis doctoral relacionada con la crisis financiera del siglo XXI y sus fundamentos lógicos e históricos de las conexiones nucleares con la evolución del sistema capitalista. Hilferding es un eslabón que permite conectar la Ley del valor de Marx con la fenomenología contemporánea de las crisis inmanente al modo de producción capitalista.

2 Universidad Nacional Autónoma de México, Facultad de Economía, Ciudad de México. Candidato a Doctor en el programa de Posgrado en Economía, especialización en el área de economía política. Director del Centro de Estudios del Capitalismo Contemporáneo. Profesor de Economía Política en la FES-ACATLÁN de la UNAM.

3 Las transformaciones cuantitativas y cualitativas responden al arsenal de leyes dialécticas que son fundamento del análisis del materialismo histórico. Recomiendo ampliamente la obra de Elí de Gortari (1979, p.49) especialmente el capítulo tercero intitulado Las leyes dialécticas.

4 un detalle curioso es que tanto Hilferding como Petty son médicos (al igual que el padre fisiócrata, François Quesnay) quienes utilizan su concepción anatómica del cuerpo humano para pensar los sistemas sociales como un organismo integrado, por ello, las leyes económicas representan las funciones y evolución del cuerpo, lo que sin duda también va a determinar la subjetividad de ese cuerpo humano.

5 Franck Fischbach (2012), en su artículo intitulado De cómo el capital captura el tiempo señala: “Que el trabajo guarda relación con el tiempo es una evidencia, pero que esa relación del trabajo con el tiempo sea esencial y no sólo accidental resulta menos evidente. Eso es lo que hizo Hegel en la Fenomenología del espíritu, en la que esa relación esencial del trabajo con el tiempo aparece por contraste con el simple consumo: trabajo y consumo tienen en común la cualidad de ser relaciones negativas con el objeto, pero, en el caso del consumo, esa relación negativa se realiza en la aniquilación inmediata y sin demora de la cosa, mientras que, en el caso del trabajo, la relación negativa con la cosa se estabiliza y, por tanto, perdura en el tiempo."(p.85) Es el tipo de estabilización el que le interesa estudiar al materialismo histórico.

6 Para el tema del utilitarismo y su relación interna con la usura ver Bentham (2009).

7 Se recomienda la lectura del capitulo XXV, intitulado Crédito y capital ficticio en la sección quinta del Tomo III de El Capital (1980) para poder comprender la íntima relación entre la elasticidad del mercado mundial y el mecanismo que fundamenta la posibilidad de la especulación bursátil.

8 Ver entrevista: Bassets, Marc, (24/11/19), Thomas Piketty: Propongo un impuesto que permita dar a todo el mundo 120.000 euros a los 25 años", El País, url: https://elpais.com/elpais/2019/11/22/ideas/1574426613_189002.html

9 Ver María de Lourdes Treviño Villareal (2011) en su libro intitulado Tres décadas de escándalos financieros: are derivatives to Blame? Analiza cómo el tipo de especulación financiera típico de la última gran crisis del 2008 nace gracias al planteamiento de modelos matemáticos de análisis de riesgo, pero también señala cómo hay una relación entre los primeros casos de estafa financiera, como es el caso de Enron, en el cual este se encontraría bajo la protección de la Reserva Federal.

10 Para que el lector se de una idea de la violencia con la que los capitales se mueven alrededor del mundo en búsqueda de rentabilidad considérese el tema de los fondos buitre que mediante la bursatilización del crédito de deuda soberana generan una serie de presiones sobre de ciertos países -como fue el caso de Argentina y Grecia-para hacer las reformas que le convengan al capital encima de las necesidades de la población, para esto revisar a Hernández (2015).

11 El tema del militarismo del capital es tratado con amplitud por Nicolai Bujarin (1969) en su tratado intitulado La economía mundial y el imperialismo donde describe la evolución del sistema hacia su forma militar como mecanismo para la determinación de la repartición geopolítica.

12 Para una recapitulación de los elementos abstractos de la teoría de la crisis a lo largo de El Capital considérese la obra del Dr. Pedro López Díaz (2006) intitulada Capitalismo y crisis: la visión de Karl Marx. Es necesario recordar que la teoría de la crisis en Marx se encuentra desperdigada a lo largo de su obra en diferentes momentos de análisis. Como se sabe, la categoría de crisis y mercado mundial eran los niveles más concretos por lo que requieren de un alto grado de determinaciones previas.

13 En el epílogo a la segunda edición del primer tomo de El Capital. Marx (2001) se percata que la recepción de su obra había sido difícil por un problema de mala comprensión del método con el que está construido. En ese mismo texto Marx, tratando de dar claridad, explica que su método es un método comparativo entre fases de desarrollo y que las leyes económicas no son otra cosa más que leyes de movimiento, por lo que la comparación entre fases permite 


\section{Pensamiento Crítico Vol. 24. $\mathrm{N}^{\circ} 2$}

conocer la validez de dichas leyes puesto que lo que se tiene que demostrar es que cómo una fase deviene lógicamente de la anterior. Hilferding, siguiendo esa tradición, basa su libro haciendo una comparación entre fases: la libre competencia contra la anulación de la misma mediante la asociación de capitales.

14 Ver: Chacón, Vinicio (24/11/19) [Entrevista a Boaventura de Sousa Santos], El Neoliberalismo esta mostrando su nueva fase, la incompatibilidad con la democracia, Semanario Universidad, url: https://semanariouniversidad.com/ universitarias/el-neoliberalismo-esta-mostrando-su-nueva-fase-la-incompatibilidad-con-la-democracia/ 
